\title{
The Study of the Electrical Properties of Schottky Diodes Based on Silicon with Amorphous and Polycrystalline Material
}

\author{
I.G.Pashaev \\ The Baku State University, AZ1148 Baku, Azerbaijan \\ Corresponding Author: islampashayev@rambler.ru
}

Copyright (C) 2013 Horizon Research Publishing All rights reserved.

\begin{abstract}
The summary of the given work is devoted to the obtaining of the $\mathrm{Ni}_{\mathrm{x}} \mathrm{Ti}_{100-\mathrm{x}}-\mathrm{nSi}$ Schottky diodes (DSH) and studying the electrophysical properties (where $\mathrm{x}=4 ; 19$; 37 ; 74; 96) of schottky diodes made on the basis of amorphous and polycrystalline metal alloys at low direct pressure. By means of X-rayphase analysis, it is established that the film of $\mathrm{Ni}_{37} \mathrm{Ti}_{63}$ alloy has amorphous structure, and the other films have polycrystalline one. Critical parameters of the Schottky diodes in dependence on composition and structure of metal films are determined.As a result, it is revealed that electrophysical properties of $\mathrm{Ni}_{\mathrm{x}} \mathrm{Ti}_{100-\mathrm{x}}-\mathrm{x} / \mathrm{n}-\mathrm{Si}$ Schottky diodes are connected with change of composition and structure of metal films; Alloy has amorphous structure. The height of a potential barrier is found by two methods (a method $\mathrm{I}-\mathrm{V}$, and $\mathrm{I} \sim \mathrm{T}$ ). The received results show that the barrier height is rather sensitive to structure of a metal alloy, in comparison with a polycrystalline film of metal, in case of contact of an amorphous film of metal to silicon the border of separation is rather homogeneous. Hence, it is possible to assume that occurrence of a superfluous current in DSH after an annealing at temperature $673 \mathrm{~K}$ and is above connected with change of structure of a metal film of an alloy.
\end{abstract}

Keywords Schottky Diodes Direct Pressure, Richardson's Constant, Amorphous Structure, Barrier Height, Border Has Undressed, Non-uniform Polycrystalline film, Annealing Contact metal - semiconductor Composition and Structure

\section{Urgency}

An increase in the reliability and improvement of the quality of semiconductor devices, including those based on Schottky barriers, remains an urgent problem in contemporary semiconductor technology.Formation of amorphous structure of metals and alloys leads to fundamental changes of magnetic, electric, mechanical, superconducting and other properties. Some of them have appeared very interesting both for science, and for practice. Value of other properties is not completely opened yet. In literature devoted the physicist and technology of contact metal - semiconductor only a role of the semiconductor, occurring in processes has been studied. The role of metal in most cases is neglected. The role of metals and its crystal structure on processes or have not been considered or have been badly studied [3-10]. To identify the role of metal, properties of Schottky diodes, irrespective of the structure and area of contact of metals have been studied. It is shown, that the main parameters of Schottky diodes, such as the density of a flow of saturation of height of a barrier, breakdown potential, factor of inideality depend on the area of contact and thickness of a metal film. Experimental results have been explained by heterogeneity of the contact. According to this model the contact is regarded as parallel the elementary contacts are connected to various heights of a barrier and other parameters. To increase the quality of Schottky diodes it was suggested to use amorphous films of metals. It has been found, that Schottky diodes made with amorphous films of metals are more reliability for termostability of parametres. It is important for electronics of high temperature.

Discovery of amorphous metals has made a big contribution to science about metals, essentially changed our idea of them. It has appeared, that amorphous metals strikingly differ on the properties from metal crystals for which the ordered arrangement of atoms is characteristic.

It is known, that amorphous films of metals carry out the functions of diffusion barriers properly in microelectronic structures [3-8.] and allow to make DSH with a high potential barrier (to $1-\mathrm{eV}$ ), that is of interest for solar power [7.8].

With change of temperature and structure of a film of metal there is a structural change in metal alloys in this connection parametres $D S H[.3,510]$ change also. The given work is devoted reception $\mathrm{Ni}_{\mathrm{x}} \mathrm{Ti}_{100-\mathrm{x}}-\mathrm{nSi} D S H$ and studying delectrophysical properties $\mathrm{Ni}_{\mathrm{x}} \mathrm{Ti}_{100-\mathrm{x}} \mathrm{nSi}$ DSH With 
amorphous and polikristalline films metal сплавов at low direct voltage.

\section{Experimental Process}

For manufacturing DSH as the semiconductor silicon plate of $n-$ type with orientation (111) and specific resistance $n$ - layer $0.7 \mathrm{Ohm}$ see As metal used alloy $N i_{x} T i_{100-x}$ (where $x=4 ; 19 ; 37 ; 74 ; 96$ )was used. Films of alloy $N i_{x} T i_{100-x}$ are obtained by a method of electron beam evaporation from two sources. The structure of an alloy of a film was supervised by a method of the radiographic analysis on plant DRON-2 [1-3]. The roentgenogram is resulted on fig. 1. Apparently from drawing a film of alloy $N i_{35}-T i_{65}$ it is had amorphous structure, and other films polycrystalline [1.2]. This conclusion made on the basis of that at crystals a series of maxima and minima is accurately expressed that speaks not only about a correct arrangement of the nearest atoms, but also about existence of a distant order, i.e. in crystals it is possible to spend co-ordinates, on which relative positioning of atoms same on the distance many times over exceeding size of an elementary cell. In amorphous film also, as well as in Crystals the first maxima is completely resolved, i.e. the first minima concerns an axis obstsiss. It means, that on certain distance the density of disseminated electrons is practically equal to zero. Maxima and minima are expressed by to presence of different internuclear distances, aspiring in a limit to a smooth curve. In amorphous film the near order within each elementary cell constructed also, as well as in a crystal is observed only. Outside of a cell the order is broken. It occurs, because each following cell is a little turned concerning previous, and the direction of turns often statistical As a result $\mathrm{X}$-ray system $\mathrm{Ni}-\mathrm{Ti}$ analysis is established, that in dependence on quantity of atoms $\mathrm{Ni}$ before reception of structure $\mathrm{Ni}_{35} \mathrm{Ti}_{65}$ the periods crystal cell will change not submited to the Vegard's law. [1.-5.].

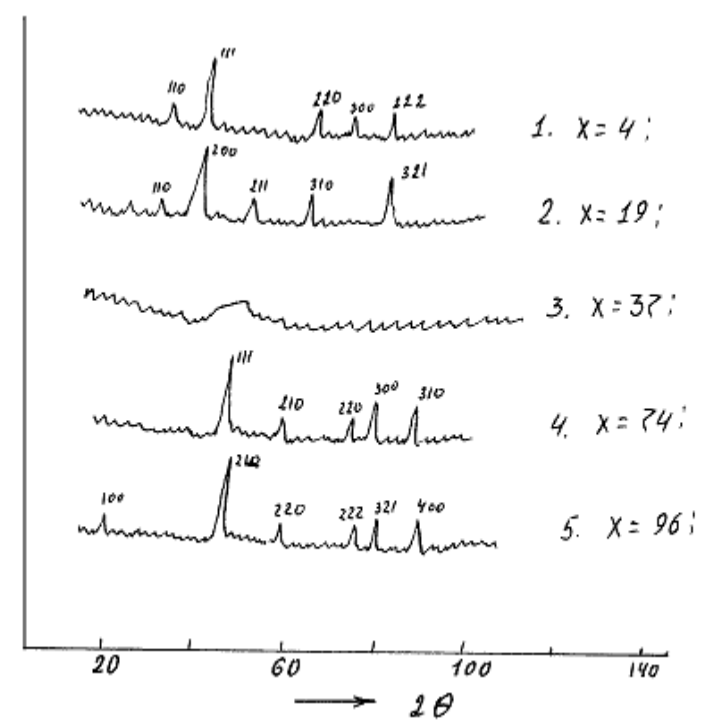

Figure 1. The roentgenogram of films of an alloy (Where $x=4 ; 19 ; 37 ; 74$; 96).

\section{Results and Their Discussions}

In the field of direct voltage $v>3 \mathrm{kt} / \mathrm{e}$ parametres of Schottky diodes are defined from current-voltage characteristic which is expressed by the formula [12]:

$$
\mathrm{I}=S A T^{2} \exp \left(\frac{\varphi_{\mathrm{b}}}{k_{\mathrm{T}}}\right)\left[\exp \left(\frac{\varphi_{\mathrm{b}}}{n k \mathrm{~T}}\right)-1\right]
$$

Where A - Richardson's effective constant, n-factor of inideality. $\varphi_{\sigma}$-barrier height. All other designations have usual sense.

For the same purpose an initial site of pressure $\mathrm{v}<\mathrm{kt} / \mathrm{e}$ where current-voltage characteristic $\boldsymbol{D S H}$ is described by the formula [3-5] can be used.

$$
I=S A T \cdot \frac{\ell}{k} \exp \left(\frac{\Phi_{\mathrm{B}}}{\mathrm{kT}}\right) \cdot V
$$

From the formula (2) follows, that resistance of transition is described by the formula:

$$
R=k / \ell A S A_{0} T \exp \left(\frac{\Phi_{\mathrm{B}}}{\mathrm{kT}}\right)
$$

From comparison of the formula (2) with (3) it is obvious, that current-voltage characteristic is a straight line with the angular factor equal to $1 / \mathrm{R}$.

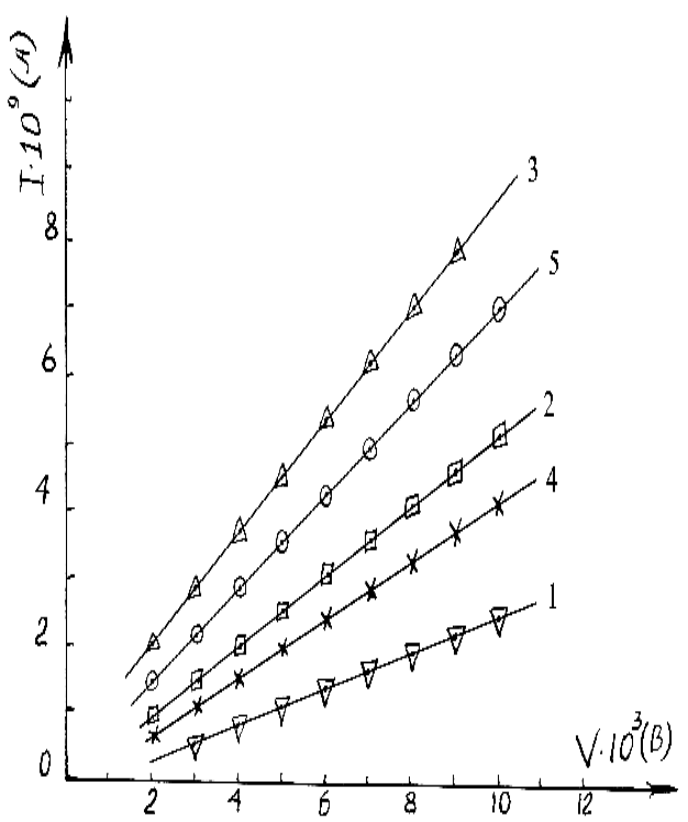

Figure 2. Current-voltage characteristicDSH at low direct voltage.1-4 2-19; 3-37; 4-74; 5-96

Fig. 2 presents experimental current-voltage characteristic $D S H$ where parameter of straight lines is percentage of components of an alloy [5-8]. The specified relation has been obtained at a room temperature for diodes with the area $\mathrm{S}=$ $1200 \mathrm{m \kappa m}^{2}$.

On fig. 3 are presented Vakh for $\alpha$ NiTi-nSi DSH before and after an annealing at temperature $673 \mathrm{~K}$. Apparently from 
the schedule at small direct pressure after a thermoannealing there is a superfluous current.

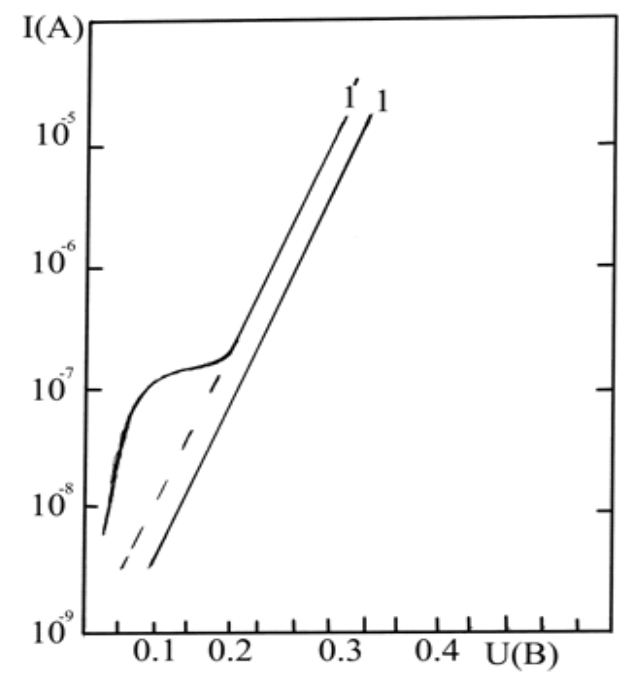

Figure 3. Vakh $\alpha$ NiTi-nSi diodes Shottki 1 to and $1 \varnothing$ after a thermoannealing at $673 \mathrm{~K}$

It is known that amorphous films of metal at certain temperatures change structure and pass in a polycrystalline condition. Hence, it is possible to assume that occurrence of a superfluous current in DSH after an annealing at temperature $673 \mathrm{~K}$ and is above connected with change of structure of a metal film of an alloy. Really, probes of structure of metal film ${ }_{\mathrm{Ni35T}}$ on installation DRON-2 before and after an annealing at temperature $673 \mathrm{~K}$ has shown that the film of metal from an amorphous or quasiamorphous condition passes in polycrystalline (fig. 4)

Value of height barriers was defined by two methods. According to the first way (method I-V), barrier resistance was defined from experimental current-voltage characteristic, then with the help of formulas (3) $\varphi_{\mathrm{B}}$ calculated with the assumption, that the area of contact $\mathrm{S}$ is equaled the geometrical area, and $\mathrm{A}=110 \mathrm{acm}^{2} \mathrm{~K}^{2}$.

Thus values $\varphi_{\mathrm{B}}$ for $\boldsymbol{D S H}$ (where $x=4 ; 19 ; 37 ; 74 ; 96$ ) are found. The essence of the second way is that as follows from the formula (3), relations between InRT and 1/T is described by a straight line, which inclination defines height of potential barrier $\varphi_{\mathrm{B}}$ (a method 1-T) [5.11]. Corresponding results are shown in table 1 .

Table 1. Altitude of the potential barrier, found methods (1-V) and (1-T)

\begin{tabular}{|c|c|c|c|c|c|}
\hline $\mathrm{x} \%$ & 4 & 19 & 37 & 74 & 96 \\
\hline$\varphi_{\mathrm{B}}(1-\mathrm{V})$ & 0,61 & 0,65 & 0,69 & 0,64 & 0,63 \\
\hline$\varphi_{\mathrm{B}}(1-\mathrm{T})$ & 0,54 & 0,58 & 0,60 & 0,53 & 0,51 \\
\hline
\end{tabular}

As seen from the table height of the potential barrier, found by methods $(1-\mathrm{V})$ and $(1-\mathrm{T})$, the greatest height corresponds to $D S H$ where the alloy has amorphous structure.

From the literature [11] it is known that $\mathrm{Ti}$ has объемноцентрированную lattice $\mathrm{J}$ with the period of an elementary cell and $=3,33 \AA$, Ni has гранецентрированную lattice $\mathrm{F}$ with the period and $=3,52 \AA$. Also there are data on existence гексагональных versions of these components. However, received by us дифрактограммы pure elements $\mathrm{Ni}$ and Ti have shown that reflexes дифрактограммы are displayed on the basis of cubic primitive lattices (Tab. 2), therefore, having assumed as a basis a cubic lattice, проиндицировали the roentgenograms corresponding to

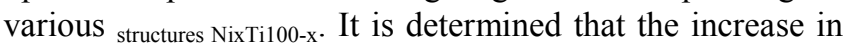
quantity $\mathrm{Ni}$ in the field of 4, 19, 37 leads to crystallisation of the sample. However there are no natural changes of the periods of a lattice.
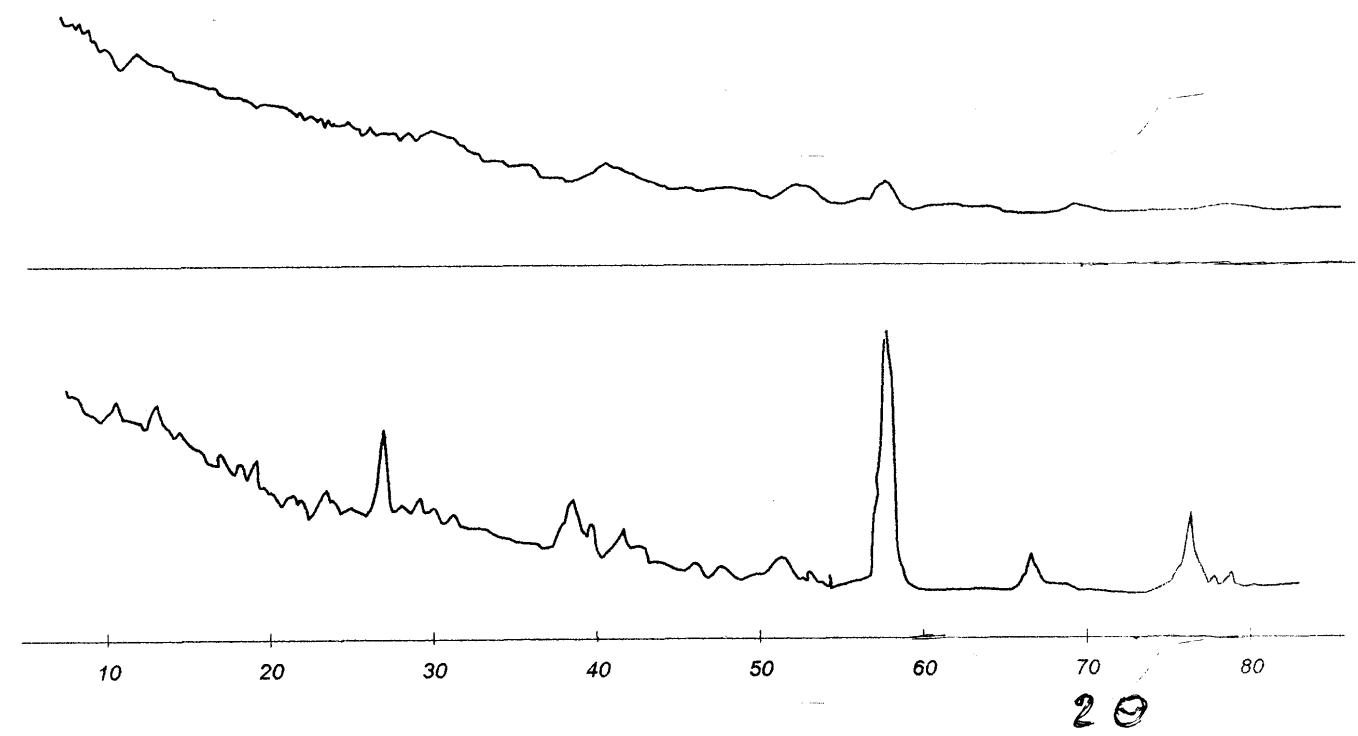

Figure 4. The rentgenostrukturnyj analysis of amorphous metal films a (NiTi); 1 - to - after a thermoannealing at $673 \mathrm{~K}$ 
Table 2. Interplane distances $d(\AA)$, indexes (hkl), the periods (a) and types, Lattices on roentgenograms of alloys NixTi100-x

\begin{tabular}{|c|c|c|c|c|c|c|c|c|c|}
\hline № & 1 & \multicolumn{3}{|c|}{2} & 4 & 4 & \multicolumn{3}{|c|}{5} \\
\hline $\mathrm{X} a>\%$ & 4 & \multicolumn{3}{|c|}{19} & 37 & 74 & \multicolumn{3}{|c|}{96} \\
\hline & $\mathrm{d}(\AA)$ & hkl & $\mathrm{d}(\AA)$, & hkl & & \multicolumn{2}{|c|}{$\mathrm{d}(\AA)$} & hkl & hkl \\
\hline 1. & 2,356 & 110 & 2,797 & 110 & & 3,083 & 110 & 2,058 & 111 \\
\hline 2. & 1,690 & 200 & 2,254 & 111 & & 2,311 & 200 & 1,564 & 210 \\
\hline 3. & 1,364 & 211 & 1,408 & 220 & & 1,824 & 211 & 1,266 & 220 \\
\hline 4. & 1,175 & 220 & 1,275 & 300 & & 1,435 & 311 & 1,199 & 300 \\
\hline 5. & 1,054 & 310 & 1,163 & 222 & & 1,175 & 321 & 1,100 & 310 \\
\hline & $\begin{array}{c}3,33 \AA \\
j\end{array}$ & & $\begin{array}{c}3,92 \AA \\
p\end{array}$ & & & $\begin{array}{c}4,45 \AA \\
\mathrm{p}-\end{array}$ & & $\begin{array}{c}3,52 \AA \\
\mathrm{p}\end{array}$ & \\
\hline
\end{tabular}

Change of the periods and types of lattices is connected with statistical distribution of separate atoms in unequal кристаллографических positions (J

$\square \mathrm{P}: \mathrm{F} \square$

As it was marked above, depending on quantity of atoms $\mathrm{Ni}$ before obtaining of structure $\mathrm{Ni}_{37} \mathrm{Ti}_{65}$ the periods of a crystal lattice linearly change. With increase in quantity of atoms $\mathrm{Ni}$ the barrier altitude is increased. At structure Ni37Ti65 the received sample is amorphous. From the table it is visible that to this structure DSH there corresponds the greatest altitude of a barrier.With the further increase in quantity $\mathrm{Ni}$ (in the field of $37,74,96$ ) the barrier altitude decreases DSH. This results from the fact that system Ni - Ti forms firm solutions.

\section{Conclusions}

Comparing results рентгенофазового the analysis and value of parametres DSH it is possible to conclude that change of parametres NixTi100-x-nSi DSH are The results received for $\mathrm{V}<\mathrm{kt} / \mathrm{e}$ allow to conclude, that in comparison connected with change of structure and structure of a film of metals with a polycrystalline film of metal, in case of contact of an amorphous film of metal with silicon, the border of separation is rather homogeneous, barrier heights are rather sensitive to structure of a metal alloy. With the further increase in quantity $\mathrm{Ni}$ (in the field of $37,74,96$ ) the height of a barrier DSH decreases . This results from the fact that system $\mathrm{Ni}$ - Ti forms firm solutions. Results of X-ray analysis and dependence of parametres DSH on a percentage condition show, that change of parametres NixTi100-X-nSi DSH are connected with change of structure and structure of a film of metals

\section{REFERENCES}

[1] Amorphous metals Under the editorship of Masumota T.Per. with япон. M: Metallurgy, , 328.p. 1987

[2] Amorphous metal alloys. Under the editorship of F.E.Ljuborskogo. M: metallurgy, 620.p. 1987.

[3] S.G Askerov., S.S., Aslanov, I.G Pashaev "Electric of property of contact piece of silicon with amorphous metal alloy Al-Ni " Theses of reports of All-Union conference "Physics and application of contact piece metal-semiconductor", Kiev, p.16.1987.

[4] R.K.Mamedov, Contact piece metal-semiconductor with an electrical field of stains. Baku, . 203.p. 2004.

[5] S.G Askerov., S.G Aslanov., I.G Pashaev."Electrophysical propert of barrier structures on the basis of silicon with an amorphous metal alloy aluminium-nickel" the Electronic engineering-10, Microelectronic devices, Vol.6, №78, pp.46-48. 1989.

[6] I.G.Pashaev, Askerov S.G, R.F."Mehtiev Influence change of structure and metal structure on electrophysical properties of Shottki made on the basis кремия" The bulletin of the Baku University. №3, pp. 157 - 161. 2006.

[7] Sh. G.Askerov I.G.Pashaev "Electropnysial properties of silicon contact prepared wnit amorpnous metallic NiTi allox" Conference Proceeding Second International Conference on Technical and Physical Problems in Power Engineering. Tabriz-Iran 6-8 september p p.367 - 368. 2004.

[8] D.K Wickenden., M.J Sisson. "Amorphous metal-semiconductor contacts for high temperature electronics"Solid State Electron. Vol.27. №6. p.515-518. 1984.

[9] N.A.Torhov "The Nature of direct and return currents of saturation in contact pieces metal-semiconductor with a barrier of Shottki" Physics and engineering of semiconductors Vol.44. №6. - pp. 767-7742010.

[10] P.N.Krylov. "Physical models of the thermoprocessed contact piece metal-silicon" the Bulletin of the Udmurt University. Physics. №4, pp. 125-136. 2006.

[11] A.Gine Rengenografija of crystals. Moscow 603.p1961

[12] S.M.Zi. Physics of semiconductor devices. Under the editorship of R.A.Surusa. Moscow <World $>$ Volume. 1. 456.p. 1984. 